\title{
Inner-organizational Institutional Environment and Its Impact on the Companies' Innovation Capacity
}

\author{
Zheng-qun ZHAN ${ }^{1,}$ a , Min $\mathrm{LI}^{1,}{ }^{1,}{ }^{*}$ and Jun-ni PAN ${ }^{1}$ \\ ${ }^{1}$ School of Economics and Commerce, South China University of Technology, P.R. \\ China, 510004 \\ a'Zhanzq@scut.edu.cn; 'bim@scut.edu.cn \\ ${ }^{*}$ Corresponding Author
}

Keywords: Institutional factors, Innovation capacity, Positional power, Result-oriented Incentive system.

\begin{abstract}
Institutional factors in organizations can be divided into two aspects: one is the ideological system such as the value, culture and other aspects, which can be regarded as an informal system because the content of this aspect always is unwritten and tacit; the other is the system of power distribution, incentive mechanism, etc., which can be regarded as a formal system. This research discusses the influence of above two aspects on organizational innovation capacity. Based on a sample of 392 Chinese enterprises, this research found that all these informal and formal institutional factors have positive influence on the firm's innovation capacity, and they also have positive interactions between each other.
\end{abstract}

\section{Introduction}

Institution has an important influence on the economic performance[1]. As an open system, the innovation ability and performance of organizations are influenced by the external and internal institutional environment[2,3]. According to the institutional theory, the structure and behavior of the organization is not only the result of various competitive forces and efficiency mechanisms, but also influenced by the structure of social belief and rule system, and the influence included the following two aspects: how to forming the organization and operating it. The new institutional economics scholars believe that the institutional structure of the enterprise has a key impact on the production efficiency, the existing system arrangement will affect the incentive mechanism of the elements, and then affect the efficiency of the production service flow into the enterprise $[4,5]$. In the case of other conditions unchanged, the output of the contract with the elements of the contract changes with the changes of the system and the organization structure of the enterprise. The elements of organizational system have an important influence on the knowledge accumulation, innovation and production. This study mainly discusses the influence mechanism and effect of the institutional environment in the organization.

\section{Organizational Institutional Environment and Innovation Capacity}

The enterprise cannot survive without cooperation, production and innovation needs joint efforts of all the members in enterprises. Especially, the efficiency and results of enterprises more or less depending on how to better integrate the members' efforts together and efficient cooperation. Therefore, the institutional structure of cooperation has significant influence on enterprise innovation ability and performance. 
Institutional factors in organizations can be divided into two aspects: one is the ideological system such as the value, culture and other aspects, which can be regarded as an informal system because the content of this aspect always is unwritten and tacit; the other is the system of power distribution, incentive mechanism, etc., which can be regarded as a formal system. This research will discuss the influence of above two aspects on organizational innovation capacity.

According to previous studies on entrepreneurship, there are five factors that influence innovation performance, namely, corporate culture, organizational support, position power, reward-incentive system, resource availability, etc.[6,7]. From the view of institutional theory, the informal institutional factors in organization include corporate culture and organizational support, and the formal institutional factors include positioner power and reward-incentive system.

\section{Hypotheses}

\section{The Effect of Informal Institution on Innovation Performance}

The role of culture is crucial for the development of innovation[8]. Impact of corporate culture on business performance is very significant, and has been verified by many studies. For instance, Bartlett and Choshal (1997) argued that entrepreneurial enthusiasm simply from the senior management team and the general staff is not enough. Business-oriented culture throughout the organization must be created, and people should work together to help improve organizational performance. Yildiz, ML (2014) studied the correlation between organizational culture and intrapreneurship, they made separate correlation analysis of the internal elements with the right distance, uncertainty avoidance, individualism, masculinity, long-term orientation, and concluded that the organizational culture has a certain impact on the internal innovation $[9,10]$.

However, we suggest that organizational culture is a relative grand topic, including many avenues of research, and organizational culture can be composed by many aspects, so we will study from the perspective of organizational support (Yildiz 2014).

Organizational support (OS) refers to favorable conditions of acquiring organizational resources, generating new ideas and carrying out new projects relatively easily. Some scholars divide organizational support into the following dimensions: management support for new business ideas, the arrangement of free time, flexibility in work decision-making, the proper use of performance reward system and degree of risk taken. Hornsby (2002) indicated that the degree of the management's willingness to promote entrepreneurial activities includes many forms, such as promoting innovative ideas, providing the necessary professional knowledge and institutionalizing the company's entrepreneurial activities. To a certain extent, the degree of the management support for intrapreneurship has a positive effect on the emergence and development of intrapreneurship. The willingness of management to promote projects has a profound significance on the development of intrapreneurship. The availability of resources such as human, finance and time is also an important aspect of organizational support. Thus, companies must make sure that employee feel that they can get all the resources needed for entrepreneurship, which meets the most basic material conditions.

We suggest that all these above can be incorporated into the organizational support. Therefore, the following assumption is proposed: 
Hypothesis 1: organizational support has a significant positive impact on innovation performance of high-tech enterprises.

\section{The Effect of Position Power on Innovation Performance}

The factor that enterprises empower employees on particular positions also has a subtle influence on innovation performance. Enterprises with different corporate cultures and different organizational management characteristics would empower different responsibilities to some positions. In general, enterprises in which employees have greater rights, such as greater autonomy, will have a greater possibility of intrapreneurship.

The greater autonomy the enterprises give to employees; the higher risk they will have to take. Therefore, authorization and risk taken are the two aspects that companies empower their employee. Thereby, the following assumption is proposed:

Hypothesis 2: The more willing enterprises are to take risk and empower their employee, the higher innovation performance they will have.

\section{The Effect of Results-oriented Incentive System on Innovation Performance}

Rational use of incentive system as well as whether taking into account the objectives, feedback, emphasis on personal responsibility, and results-oriented motivation have a great influence on intrapreneurship (Hornsby, 2002). It always can bring better and long-standing innovation performance based on incentive system that is results-oriented. Therefore, the following assumption is proposed:

Hypothesis 3: Results-oriented incentive system helps to improve the innovation performance of enterprises.

\section{Data and Methods}

\section{Variables}

The process of developing a scale was divided into three steps. First, we summarized the past research literature to find representative scales. There were more research outcomes on the factors of organizational support, position power and achievement-oriented incentive system. We compared and analyzed scales developed by previous scholars, and then selected according to the research topic. Secondly, by using the Delphi method, experts and senior business managers were invited to analysis the selected scales to determine the initial scale. Finally, a small sample was selected to do the pre-test. In this study, 50 high-tech enterprises (46 questionnaires recovered) were selected as the predicted sample, based on which reliability and validity test were conducted. Table 1 shows the scale identified after the pre-test.

Previous studies showed that organizational support can be divided into resources support (financial, time, etc.), management support (participation in decision making, respect for the views of subordinates, etc.), as well as supportive atmosphere within the organization, such as support from communities and across departments.

Position power, authority, as well as risks are related with job autonomy, which means that if enterprises authorize employees the privilege of innovation, they will bear the related risks. Therefore, we measure the position power of employees through the factor of autonomy.

Results-oriented incentives system is mainly oriented to innovation-promoting, including remuneration, incentives and other rewards, etc. 
The indicators of innovation performance of enterprises include process competence indicators and innovative financial performance indicators. The former includes new product ratio, the competence to introduce new products to the market, and the competence of innovative application, while the latter includes profit margins and sales growth rate. The scale in detail is showed in Table 1.

Table 1. Description of variables

\begin{tabular}{c|l}
\hline Factors measured & Items after pre-test \\
\hline \multirow{4}{*}{$\begin{array}{c}\text { Organizational } \\
\text { support } \\
\text { (OS) }\end{array}$} & $\begin{array}{l}\text { People have a strong sense of belonging and mutual support. } \\
\text { Company's people. }\end{array}$ \\
\cline { 2 - 2 } $\begin{array}{c}\text { Position } \\
\text { power } \\
\text { (PP) }\end{array}$ & $\begin{array}{l}\text { The superiors show true respect for others when making decisions, } \\
\text { regardless of the status of others. }\end{array}$ \\
\cline { 2 - 2 } $\begin{array}{c}\text { Resulted-oriented } \\
\text { incentive system } \\
\text { (RI) }\end{array}$ & $\begin{array}{l}\text { When making decisions, the superiors consider sincerely for employee, } \\
\text { and give supportive feedback action. }\end{array}$ \\
\cline { 2 - 2 } & I have the freedom and right to decide how I do my work. \\
\cline { 2 - 2 } & $\begin{array}{l}\text { The project team has considerable freedom to make decisions and adopt } \\
\text { action without approval. }\end{array}$ \\
\cline { 2 - 2 } $\begin{array}{c}\text { Employees are payed based on work performance. } \\
\text { Innovation }\end{array}$ & The innovation will be rewarded. \\
\cline { 2 - 2 } $\begin{array}{c}\text { Performance } \\
\text { (PI) }\end{array}$ & The success of innovative projects will be well rewarded. \\
\cline { 2 - 2 } & New Product ratio \\
\cline { 2 - 2 } & $\begin{array}{l}\text { The competence to introduce new products to the market } \\
\text { methods }\end{array}$ \\
\cline { 2 - 2 } & Sales growth rate \\
\cline { 2 - 2 } & Profit margin \\
\hline
\end{tabular}

\section{Descriptive statistics}

352 questionnaires were obtained with the help of a professional investigation company, and 203 questionnaires were obtained in MBA classes. After excluding 121 questionnaires done by employees of non-high-tech enterprises, and 38 non-standard and incomplete questionnaires, a total of 396 were accepted. The descriptive statistics of the sample are shown in Table 2 below.

From the perspective of the composition of the sources of the sample, $93 \%$ of the participants are managers, and more than 50 percent are middle-senior managers, which means that they are well aware of the firm's management and operation conditions, beneficial to improve the effectiveness of the investigation. Males account for the major part (almost 60\%). Participants aged 26-35 years and 36-45 years are the most, in line with the company's management age characteristics. According to the educational level, undergraduates, postgraduates account for 95 percent, which indicates that the questionnaire has gotten a high level of understanding. 
Table 2. Sample Description

\begin{tabular}{|c|c|c|c|}
\hline Factors measured & Description & Frequency & $\%$ sample \\
\hline \multirow{5}{*}{$\begin{array}{c}\text { Company size } \\
\text { (number of people) }\end{array}$} & Less than 20 & 4 & $1.01 \%$ \\
\hline & $20-150$ & 61 & $15.40 \%$ \\
\hline & $151-1000$ & 217 & $54.79 \%$ \\
\hline & $1001-10000$ & 80 & $20.20 \%$ \\
\hline & More than 10000 & 34 & $8.58 \%$ \\
\hline \multirow{5}{*}{ position } & Frontline staff & 29 & $7.3 \%$ \\
\hline & Supervisor & 74 & $18.7 \%$ \\
\hline & Middle managers & 95 & $24 \%$ \\
\hline & Middle-senior managers & 90 & $22.7 \%$ \\
\hline & Senior managers & 108 & $27.3 \%$ \\
\hline \multirow{2}{*}{ gender } & Male & 238 & $60.1 \%$ \\
\hline & Female & 158 & $39.9 \%$ \\
\hline \multirow{5}{*}{ age } & Less than 25 & 8 & $2 \%$ \\
\hline & $26-35$ & 216 & $54.5 \%$ \\
\hline & $36-45$ & 151 & $38.1 \%$ \\
\hline & $46-55$ & 21 & $5.3 \%$ \\
\hline & More than 56 & 0 & $0 \%$ \\
\hline \multirow{3}{*}{ Educational level } & Postgraduate degree & 94 & $23.7 \%$ \\
\hline & Undergraduate degree & 282 & $71.2 \%$ \\
\hline & Associate degree & 20 & $5.1 \%$ \\
\hline Overall & & 396 & $100 \%$ \\
\hline
\end{tabular}

\section{Reliability}

To measure the reliability of the scale, reliability test is carried out. The test results are shown in Table 3.

Reliability analysis indicates that except that the Cronbach's Alpha of results-oriented incentives is slightly lower than 0.7, the rest of the scales' Cronbach's Alpha were above 0.7. T test results show that the reliability of these indicators are acceptable.

Table 3. Reliability testing $(\mathrm{N}=396)$

\begin{tabular}{l|c|c|c|c|c}
\hline Element measured & indicators & Cronbach's & \multicolumn{3}{|c}{ Hotelling T-square test } \\
\cline { 4 - 6 } & & Alpha & Hotelling' T-square & F & Sig. \\
\hline $\begin{array}{l}\text { Organizational } \\
\text { support(OS) }\end{array}$ & 4 & 0.825 & 17.203 & 5.705 & 0.001 \\
\hline $\begin{array}{l}\text { Resulted-oriented incentive } \\
\text { system(RI) }\end{array}$ & 3 & 0.692 & 60.32 & 30.084 & 0.000 \\
\hline Position power(PP) & 3 & 0.707 & 67.951 & 33.890 & 0.000 \\
\hline $\begin{array}{l}\text { Innovation } \\
\text { Performance(IP) }\end{array}$ & 5 & 0.892 & 10.364 & 2.323 & 0.005 \\
\hline
\end{tabular}

\section{Validity}

Delphi method shows that the scale has good validity ostensibly. Predictive results show that the scale has certain structure validity. This paper applies factor analysis to analyze the structure validity. 
Table 4. Factors extracted using Orthogonal rotation method $(n=396)$

\begin{tabular}{c|c|c|c|c|c|c}
\hline \multirow{2}{*}{ Factors } & \multicolumn{3}{|c|}{ Initial eigenvalues } & \multicolumn{3}{c}{ Eigenvalues after rotation } \\
\cline { 2 - 6 } & total & variance \% & $\begin{array}{l}\text { Cumulative } \\
\text { variance \% }\end{array}$ & total & variance \% & Cumulative variance \% \\
\hline 1 & 5.441 & 34.009 & 34.009 & 4.113 & 25.704 & 25.704 \\
\hline 2 & 3.237 & 20.229 & 54.238 & 2.601 & 19.256 & 44.961 \\
\hline 3 & 1.361 & 13.256 & 67.494 & 2.015 & 16.593 & 61.554 \\
\hline 4 & 1.067 & 9.417 & 76.911 & 1.977 & 15.358 & 76.911 \\
\hline
\end{tabular}

The test results of KMO and Bartlett's (KMO value) in factor analysis is 0.889 , with an approximate chi-square value of 2945.39, degrees of freedom of 120, and significance of 0.000 . This shows that the factor analysis results are valid. Orthogonal rotation method is used and it extracts four factors shown in Table 4.Rotated ingredient matrix is shown in Table 5 .

Table 5. Rotated ingredient matrix

\begin{tabular}{|c|c|c|c|c|}
\hline & \multicolumn{4}{|c|}{ factors } \\
\hline & 1(IP) & $2(\mathrm{OS})$ & $3(\mathrm{RI})$ & $4(\mathrm{PP})$ \\
\hline $\mathrm{P} 1$ & .846 & & & \\
\hline $\mathrm{P} 2$ & .835 & & & \\
\hline P3 & .826 & & & \\
\hline $\mathrm{P} 4$ & .795 & & & \\
\hline P5 & .791 & & & \\
\hline Os1 & & .788 & & \\
\hline OS2 & & .763 & & \\
\hline OS3 & & .733 & & \\
\hline OS4 & & .624 & & \\
\hline RI1 & & & .778 & \\
\hline RI2 & & & .717 & \\
\hline RI3 & & & .641 & \\
\hline PP1 & & & & .799 \\
\hline PP2 & & & & .772 \\
\hline PP3 & & & & .692 \\
\hline
\end{tabular}

*Extraction method: principal component

*Rotation Method: A Kaiser standardized orthogonal rotation method

According to the analysis outcome of reliability and validity above, we introduce the average of these metrics to represent different scores of the factors, and firm size as a control variable, and do the relevant analysis. Correlation coefficient matrix of every element is shown in Table 6.

Table 6. Correlation matrix

\begin{tabular}{l|l|l|l|l|l|l|l}
\hline & Mean & S.D. & OS & RI & \multicolumn{1}{c|}{ PP } & IP & FRIMSIZE \\
\hline OS & 2.2235 & .82346 & 1 & & & & \\
\hline RI & 2.1684 & .76766 & $.629^{* *}$ & 1 & & & \\
\hline PP & 2.4512 & .85627 & $.565^{* *}$ & $.514^{* *}$ & 1 & & \\
\hline IP & 2.4869 & .91951 & $.230^{* *}$ & $.229^{* *}$ & $.201^{* *}$ & 1 & \\
\hline FRIMSIZE & 3.20 & .838 & $-.233^{* *}$ & $-.130^{* *}$ & $-.225^{* *}$ & $.167^{* *}$ & 1 \\
\hline
\end{tabular}

*. Significant at $\mathrm{P} \leq 0.05$; **. Significant at $\mathrm{P} \leq 0.01$; *** Significant at $\mathrm{P} \leq 0.001$.

\section{Result and Discussion}

This study designs four models of main effect analysis. The results are shown in table 7 . 
The regression result of model $\mathrm{M}_{1}$ shows that the organizational support has a significant positive impact on innovation performance of enterprises, ceteris paribus, thus hypothesis 1 is verified.

The main effect regression of model $\mathrm{M}_{2}$ shows that results-oriented incentive system has a significant impact on innovation performance of enterprises, ceteris paribus, thus hypothesis 2 is verified.and the main effects regression of model $\mathrm{M}_{3}$ shows that the greater position power and the more autonomy employees have, the better innovation performance of enterprises, ceteris paribus, thus hypothesis 3 is verified.

Model $\mathrm{M}_{0}$ integrates all three factors in regression analysis, while the result shows that organizational support has a more significant positive impact on the innovation performance of enterprises relative to position power and incentive system. The impacts of the remaining two factors are less significant.

Although the variances of the four models above are relatively low, they are highly significant, and still have a good validity of explanation.

Table 7 Main Effect Analysis Results (dependent variable: innovation performance)

\begin{tabular}{l|c|c|c|c}
\hline & $\mathrm{M}_{1}$ & $\mathrm{M}_{2}$ & $\mathrm{M}_{3}$ & $\mathrm{M}_{0}$ \\
\hline OS & $0.284 * * *(5.793)$ & & & $0.157 * *(2.383)$ \\
\hline RI & & $0.255^{* * *(5.268)}$ & & $0.104(1.65)$ \\
\hline PP & & & $0.224 * * *(4.521)$ & $0.113(1.89)$ \\
\hline Firm size & $0.234 * * *(4.757)$ & $0.20 * * *(4.133)$ & $0.251 * * *(5.075)$ & $0.243 * *(4.945)$ \\
\hline Constant & $1.063 * * *$ & $1.208 * * *$ & $1.139 * * *$ & $2.382 * * *$ \\
\hline R2/Adjusted-R2 & $0.104 / 0.100$ & $0.992 / 0.087$ & $0.088 / 0.083$ & $0.123 / 0.114$ \\
\hline \multicolumn{1}{c}{ Sig. } & $0.000(22.911)$ & $0.000(19.924)$ & $0.000(18.896)$ & $0.000(13.741)$ \\
\hline
\end{tabular}

*. Significant at $\mathrm{P} \leq 0.05$; **. Significant at $\mathrm{P} \leq 0.01 ; * * *$ Significant at $\mathrm{P} \leq 0.001$.

All the four models above show that firm size of enterprises has a positive impact on innovation performance. This indicates that the larger the enterprise and the more organizational support are, the better innovation performance is.

To further understand the Interaction between organizational support, incentive system, and position power, interaction analysis was conducted. After adding interaction terms, some of the VIP values of the general linear regressions are up to 24 or more, and most VIF values are greater than 8 , which means that there is a problem of multicollinearity. Therefore, in order to avoid this problem, we use a ridge regression to estimate. The analysis results are shown in Table 8.

Model $\mathrm{M}_{4}$ analyzes the interaction between organizational support and incentive system. Model $\mathrm{M}_{5}$ analyses the interaction between organizational support and position power. Model M6 analyses the interaction of incentive system and position power.

Results suggest that organizational support, incentive system and position power all have significant positive impacts on innovation performance of enterprises. At the same time, all these three factors have positive interaction with each other. 
Table 8. Ridge regression results ( $\mathrm{n}=396)$ (dependent variable: innovation performance)

\begin{tabular}{l|l|l|l}
\hline & \multicolumn{1}{|c|}{$\mathrm{M}_{4}$} & $\mathrm{M}_{5}$ & $\mathrm{M}_{6}$ \\
\hline OS & $0.78^{* * *}(6.531)$ & $0.075^{* * *}(5.734)$ & $0.086^{* * *}(6.029)$ \\
\hline RI & $0.066^{* * *}(5.282)$ & $0.075^{* * *}(5.034)$ & $0.065^{* * *}(4.645)$ \\
\hline PP & $0.081^{* * *}(8.354)$ & $0.068^{* * *}(7.601)$ & $0.069^{* * *(8.533)}$ \\
\hline OS X RI & $0.074 * * *(6.480)$ & & \\
\hline OS X PP & & $0.083 * * *(10.918)$ & \\
\hline PP X RI & & & $0.081 * * *(9.751)$ \\
\hline Firm size (Size) & $0.135^{* * *}(6.713)$ & $0.138^{* * *}(7.102)$ & $0.135^{* * *}(6.246)$ \\
\hline R2/Adjusted-R2 & $0.177 / 0.138$ & $0.181 / 0.142$ & $0.180 / 0.148$ \\
\hline Sig. & $0.000(3.831)$ & $0.000(3.928)$ & $0.000(4.725)$ \\
\hline
\end{tabular}

*. Significant at $\mathrm{P} \leq 0.05 ; * *$. Significant at $\mathrm{P} \leq 0.01 ; * * *$ Significant at $\mathrm{P} \leq 0.001$.

The analysis result shows that organizational support, incentive system and position power are all beneficial to the promotion of innovation performance of enterprises, while there are positive interactions among them. To enterprises, making efforts in any one of the aspects will have positive effects on the other two aspects. The hypothesizes $1,2,3$ are all confirmed.

\section{Conclusion}

This paper discusses and analyzes the inner-organization institutional factors that affect the organizational innovation performance. Based on the review and induction of the past literature, this paper summarizes the inner-organization institutional factors as two aspects: informal and formal institutional factors which are all beneficial for enterprises to improve their innovation performance. Meantime, all these informal and formal institutional factors have positive interactions between each other. Efforts made to improve any one of these three factors will have a positive impact on the other two factors, and further affect the innovation performance of enterprises.

\section{Acknowledgement}

This research was financially supported by the SSF of Guangdong Province (No.2015A070704013; 2015A070704006); Philosophy and social science project of Guangdong Province(GD15CYJ15); and Northwest A\&F University (Research on the innovation ability's evaluation and promotion mechanism of the innovative enterprises in Shaanxi Province; 2013RWYB03).

\section{Reference}

[1] N.J. Foss, G. Garzarelli, Institutions as knowledge capital: Ludwig M. Lachmann's interpretative institutionalism, Cambridge Journal of Economics, 31 (2007) 789-804.

[2] B.E. Kaufman, The organization of economic activity: insights from the institutional theory of $\mathrm{J}$ ohn R. Commons, Journal of Economic Behavior \& Organization, 52 (2003) 71-96.

[3] T.J. Fogarty, M.W. Dirsmith, Organizational socialization as instrument and symbol: An extended institutional theory perspective, Human Resource Development Quarterly, 12 (2001) 247-266. 
[4] O.E. Williamson, Comparative Economic Organization: The Analysis of Discrete Structural Alternatives, Administrative Science Quarterly, 36 (1991) 269-296.

[5] J.P. Trachtman, The theory of the firm and the theory of the international economic organization: Toward comparative institutional analysis, Northwestern Journal of International Law \& Business, 17 (1996) 470-555.

[6] S.A. Feyzbakhsh, R. Sadeghi, S. Shoraka, A Case Study of Intrapreneurship Obstacles: The RAJA Passenger Train Company, Journal of Small Business and Entrepreneurship, 21 (2008) 171-180,251.

[7] A. Tahai, M.J. Meyer, A revealed preference study of management journals? direct influences, Strategic management Journal, 20 (1999) 279-296.

[8] A. Turró, D. Urbano, M. Peris-Ortiz, Culture and innovation: The moderating effect of cultural values on corporate entrepreneurship, Technological Forecasting and Social Change, 88 (2014) 360-369.

[9] M.L. Yildiz, The Effects of Organizational Culture on Corporate Entrepreneurship, International Journal of Business and Social Science, 5 (2014).

[10] G.K. Stahl, D.N. Angwin, P. Very, E. Gomes, Y. Weber, S.Y. Tarba, N. Noorderhaven, H. Benyamini, D. Bouckenooghe, S. Chreim, M. Durand, M.E. Hassett, G. Kokk, M.E. Mendenhall, N. Mirc, C. Miska, K.M. Park, N.-S. Reynolds, A. Rouzies, R.M. Sarala, S.L. Seloti, M. Søndergaard, H.E. Yildiz, Sociocultural Integration in Mergers and Acquisitions: Unresolved Paradoxes and Directions for Future Research, Thunderbird International Business Review, 55 (2013) 333-356. 